\title{
Recent results from the electron cyclotron heated plasmas in Tokamak à Configuration Variable $(\mathrm{TCV})^{\mathrm{a})}$
}

\author{
M. A. Henderson, ${ }^{\text {b) }}$ S. Alberti, C. Angioni, ${ }^{\text {c) }}$ G. Arnoux, R. Behn, P. Blanchard, \\ P. Bosshard, Y. Camenen, S. Coda, I. Condrea, T. P. Goodman, F. Hofmann, \\ J.-Ph. Hogge, A. Karpushov, A. Manini, An. Martynov, J.-M. Moret, P. Nikkola, \\ E. Nelson-Melby, A. Pochelon, L. Porte, O. Sauter, S. M. Ahmed, Y. Andrèbe, K. Appert, \\ R. Chavan, A. Degeling, B. P. Duval, P. Etienne, D. Fasel, A. Fasoli, J.-Y. Favez, \\ I. Furno, ${ }^{\text {d) }}$ J. Horacek, P. Isoz, B. Joye, I. Klimanov, P. Lavanchy, J. B. Lister, X. Llobet, \\ J.-C. Magnin, B. Marlétaz, P. Marmillod, Y. Martin, J.-M. Mayor, J. Mylnar, P. J. Paris, \\ A. Perez, Y. Peysson, ${ }^{e)}$ R. A. Pitts, D. Raju, ${ }^{\text {) }}$ H. Reimerdes, ${ }^{\text {g) }}$ A. Scarabosio, E. Scavino,

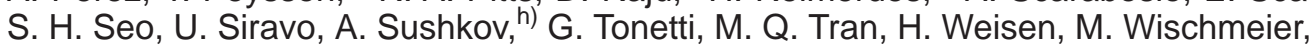 \\ A. Zabolotsky, and G. Yhuang \\ CRPP-EPFL, Association EURATOM-Confédération Suisse, Ecole Polytechnique Fédérale de Lausanne, \\ 1015 Lausanne, Switzerland
}

(Received 7 November 2002; accepted 28 January 2003)

\begin{abstract}
In noninductively driven discharges, $0.9 \mathrm{MW}$ second harmonic (X2) off-axis co-electron cyclotron current drive deposition is combined with $0.45 \mathrm{MW} \mathrm{X2} \mathrm{central} \mathrm{heating} \mathrm{to} \mathrm{create} \mathrm{an} \mathrm{electron} \mathrm{internal}$ transport barrier (eITB) in steady plasma conditions resulting in a 1.6-fold increase of the confinement time $\left(\tau_{E e}\right)$ over ITER-98L-mode scaling. The eITB is associated with a reversed shear current profile enhanced by a large bootstrap current fraction (up to 80\%) and is sustained for up to 10 current redistribution times. A linear dependence of the confinement improvement on the product of the global shear reversal factor $\left(q_{0} / q_{\text {min }}\right)$ and the reversed shear volume $\left(\rho_{q \text {-min }}^{2}\right)$ is shown. In other discharges heated with X2 the sawteeth are destabilized (respectively stabilized) when heating just inside (respectively outside) the $q=1$ surface. Control of the sawteeth may allow the avoidance of neoclassical tearing modes that can be seeded by the sawtooth instability. Results on H-mode and highly elongated plasmas using the newly completed third harmonic (X3) system and achieving up to $100 \%$ absorption are also discussed, along with comparison of experimental results with the TORAY-GA ray tracing code [K. Matsuda, IEEE Trans. Plasma Sci. PS-17, 6 (1989); R. H. Cohen, Phys. Fluids 30, 2442 (1987)]. (c) 2003 American Institute of Physics.
\end{abstract}

[DOI: $10.1063 / 1.1562167]$

\section{INTRODUCTION}

Multimegawatt electron cyclotron heating $(\mathrm{ECH})$ and current drive (ECCD) systems exist on several of today's toroidal magnetic fusion devices. The ECH system ${ }^{1,2}$ on the Tokamak à Configuration Variable ${ }^{3}(\mathrm{TCV})$ has $\sim 4.1 \mathrm{MW}$ injected power and a highly flexible launching mirror system, allowing toroidal and poloidal deposition scans during a discharge and is one of the most relevant ECH systems for the International Toroidal Experimental Reactor ${ }^{4}$ (ITER) in existence today. The EC power is supplied by three $1.35 \mathrm{MW}$ clusters (three sources each): two in the second harmonic $\mathrm{X}$-mode (X2) and one in the third harmonic X-mode (X3). A full description of the ECH system is provided in Refs. 1 and 2.

\footnotetext{
a) Paper LI1 4, Bull. Am. Phys. Soc. 47, 221 (2002).

b) Invited speaker.

c) Max-Planck-Institut für Plasmaphysik, IPP-Euratom Association, 85478 Garching, Germany.

${ }^{d)}$ Los Alamos National Laboratory, Los Alamos, New Mexico.

e) DRFC-CEA Cadarche, France.

f) Institute for Plasma Research, Bhat, Gandhinagar-382 428, Gujarat, India.

${ }^{\mathrm{g})}$ General Atomics, San Diego, California.

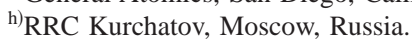

A variety of plasma heating experiments has utilized the $\mathrm{ECH}$ system in recent years. This paper will review a representative subset of the experimental topics, starting with X3 heating through the newly installed X3 system using a single mirror placed on top of the TCV chamber. The X3 system broadens the operational space of TCV with the possibility of heating plasmas at high density (up to $1.2 \times 10^{20} \mathrm{~m}^{-3}$ ), well above the cutoff density of the X2 system (4.2 $\times 10^{19} \mathrm{~m}^{-3}$ ). Injection from the top allows a long path length along the resonance layer to increase first pass absorption. X3 heating experiments involving density scans, $\mathrm{H}$-mode and highly elongated plasmas are discussed in Sec. II.

The crash of long period sawteeth can trigger seed islands large enough to destabilize the neoclassical tearing mode (NTM) at low beta on the Joint European Tokamak ${ }^{5}$ [JET (Ref. 6)]. In the moderate beta ITER scenario a mechanism to prevent the occurrence of the long sawteeth stabilized by $\alpha$-heating may remove a crucial triggering mechanism for the onset of NTMs. Hence, extensive investigation of the sawtooth behavior with ECH deposition near the $q$ $=1$ surface has been performed on TCV. Section III discusses how ECH deposition just inside the $q=1$ surface can 
destabilize the sawteeth significantly, thus shrinking the period and amplitude.

For several years there have been fully sustained ECCD discharges in TCV, with no inductively driven current. ${ }^{7,8}$ The operating scenario of these discharges has been extended to advanced tokamak regimes, by creating hollow current profiles and electron internal transport barriers (eITB) and by sustaining the plasma current with off axis ECCD deposition and an increased bootstrap current fraction. The eITB's can be further enhanced with counter ECCD on axis; steady state discharges with a bootstrap current fraction of up to $\sim 80 \%$ have been achieved. Section IV discusses these discharges and their enhancement with additional central heating as well as the dependence of the improved confinement on the magnitude of the global shear reversal factor $\left(q_{0} / q_{\min }\right)$ and the volume enclosed in the reverse shear region $\left(\rho_{q \text {-min }}^{2}\right)$.

\section{ABSORPTION OF TOP LAUNCHED X3}

The addition of $1.35 \mathrm{MW} \mathrm{X} 3$ allows heating of TCV plasmas at high densities (up to $1.2 \times 10^{20} \mathrm{~m}^{-3}$ ) beyond the X2 cutoff, $4.2 \times 10^{19} \mathrm{~m}^{-3}$. The choice of the top-launch scheme is aimed at compensating the decrease in absorption efficiency at higher harmonic number. The resonance layer is an approximately cylindrical surface on the high field side of the cold resonance and absorption is maximized when the ray path within the resonant region is longest. The X3 launch antenna consists of a single mirror (for the three $\mathrm{X} 3$ beams) placed on top of the vacuum chamber. The beams are launched in a near-vertical direction, almost tangential to the resonance layer. The increased absorption in this launch configuration is enhanced with the high elongations available on the TCV. The mirror can be displaced radially between shots permitting high field side (HFS) and low field side (LFS) launch. The beam can be swept across the resonance layer during a discharge by real-time poloidal rotation of the mirror. A detailed quantitative study of the single-pass absorption in a variety of plasma conditions with central densities higher than the X2 cutoff has been performed. These L-mode discharges heated with $\mathrm{X} 3$ alone or both $\mathrm{X} 3$ and off-axis X2 have shown single pass $\mathrm{X} 3$ absorption as high as $100 \%$.

Initial experiments were designed to test the system and compare the measured absorption ${ }^{9}$ with the absorption calculated by the TORAY-GA ray tracing code. ${ }^{10,11}$ The mirror is placed on the LFS and rotated so that the beams, $0.85 \mathrm{MW}$ in total, are swept across the resonance. In a low-density discharge $\left(\left\langle n_{e}\right\rangle \sim 2.8 \times 10^{19} \mathrm{~m}^{-3}, \kappa \sim 1.4, I_{p} \sim 230 \mathrm{kA}\right) \sim 66 \%$ single-pass absorption is measured with a diamagnetic loop ${ }^{12}$ (DML) during the modulated portion of the $\mathrm{ECH}$ pulse. The measured single pass absorption and the optimum injection angle are in good agreement with the TORAY-GA code, as shown in Fig. 1(a). The sweep was repeated with an increase in density to $\left\langle n_{e}\right\rangle \sim 8.2 \times 10^{19} \mathrm{~m}^{-3}$, the angle corresponding to optimum absorption changed by $\sim 1.0^{\circ}$ which is significant relative to the sensitivity required as shown in Fig. $1 .{ }^{13}$ To maintain optimum absorption during discharges with evolving plasma parameters (density, temperature, elongation, etc.), plans are underway to implement a real time feed-

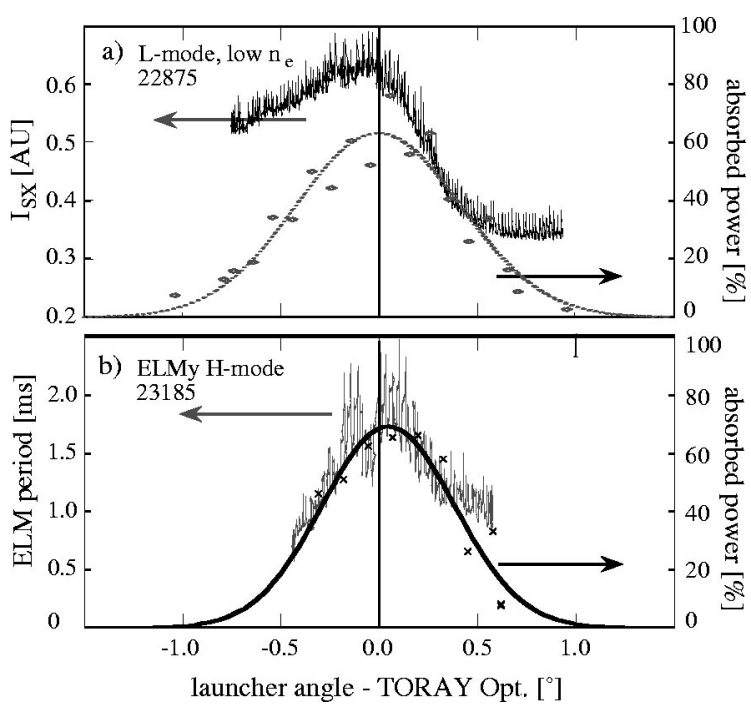

FIG. 1. Different measures of plasma response and absorbed power fraction to sweeping the X3 deposition across the resonance for two discharges, plotted against the difference between the varying launcher angle and the optimum angle for maximum absorption calculated by TORAY-GA. The plasma response is illustrated in (a) by the soft x-ray emission in a low density plasma and (b) by the change in ELM frequency in an H-mode discharge.

back control on the launcher mirror, ${ }^{14}$ which would be used to maintain maximum absorption throughout the discharge under changing plasma conditions.

With a similar swept beam technique, $0.45 \mathrm{MW} \mathrm{X3}$ has been used to heat ELMy H-mode discharges $\left(n_{e 0} \sim 5.5\right.$ $\left.\times 10^{19} \mathrm{~m}^{-3}, \kappa \sim 1.8, I_{p} \sim 440 \mathrm{kA}\right)$ achieving up to $80 \% \mathrm{ab}-$ sorption. The period of the ELMs increases as the X3 absorption increases, as shown in Fig. 1(b). The nearly full absorption of the $\mathrm{X} 3$ radiation by ELMy H-mode discharges offers the potential to achieve higher beta values on TCV.

Full X3 absorption has been achieved in X2 assisted, highly elongated discharges. In these discharges up to 1.45 MW co-ECCD X2 is deposited off-axis, resulting in current profile broadening, and thus increasing the high elongation stability limit, with $\kappa$ increasing from 1.8 to $\sim 2.5\left(n_{e 0}\right.$ $\left.\sim 6.0 \times 10^{19} \mathrm{~m}^{-3}, I_{p} \sim 380 \mathrm{kA}\right) .{ }^{15,16}$ Elongations of 2.5 are not accessible at low normalized plasma currents on TCV with Ohmic current profiles owing to the vertical instability; however, the ECCD-induced broadening of the current profile reduces the growth rate of the $n=0$ instability such that it can be controlled by the TCV vertical control system. ${ }^{17}$ Since X2 is deposited off-axis the central density can be increased above the X2 cutoff. The X 3 absorption in these discharges is enhanced by the large elongation, ${ }^{16}$ increased central density, and generation of a fast electron tail by coECCD, whose role in absorption has been previously demonstrated on TCV. ${ }^{18}$ When the $\mathrm{X} 3$ deposition is optimized for the high elongation discharge, the DML diagnostic measures up to $100 \%$ absorption using modulation of the EC power. TORAY-GA calculates $\sim 70 \%$ absorption in these discharges. The key to $100 \%$ absorption thus appears to be the $\mathrm{X} 2$ generated suprathermal electron tail, which is missing from the TORAY-GA model as it assumes a small perturbation to the electron Maxwellian distribution function. The 


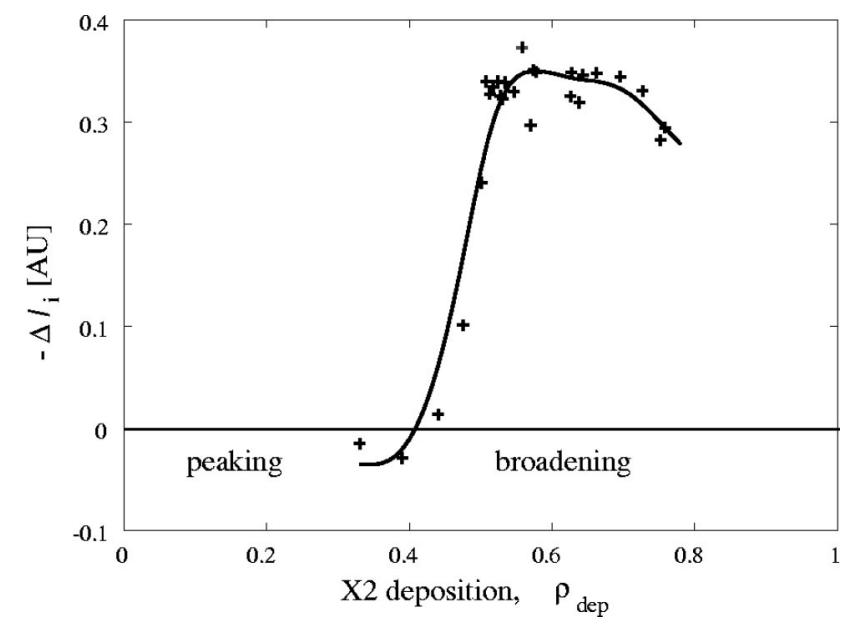

FIG. 2. The change in the plasma's internal inductance plotted against the radial deposition location of the $\mathrm{X} 2$ radiation $\left(I_{p}=300 \mathrm{kA}, \quad P_{X 2}\right.$ $=0.9 \mathrm{MW}, n_{e 0} \approx 2.5 \times 10^{19} \mathrm{~m}^{-3}$ ) (Refs. 15 and 16).

high elongation achieved with $\mathrm{X} 2$ off-axis deposition is reduced with the central deposition of $0.45 \mathrm{MW}$ X3, which peaks the current profile, increasing $l_{i}$ and therefore decreasing $\kappa$. In the future, peaking of the current profile may be avoided by decreasing $B_{\phi}$ such that the X3 absorption will be further off-axis $\left(l_{i}\right.$ is expected to remain unchanged for $\rho \sim 0.4$ ), while maintaining the X2 deposition for optimum broadening of the current profile $(\rho \sim 0.6)$, see Fig. 2. Note that $\rho$ used in this text is defined as the square root of the normalized volume of a magnetic surface.

\section{SAWTOOTH CONTROL}

Avoidance of the neoclassical tearing mode (NTM), and of the consequent confinement degradation, is one of the critical issues concerning the future operation of ITER. Recently, it has been shown that NTMs can be triggered at the crash after a long sawtooth period in low beta discharges on the JET. ${ }^{5}$ Reducing the sawtooth period may prevent the occurrence of the NTM by removing one important mechanism of the seed island formation, as was shown in the JET. ${ }^{5}$ Many experiments have shown that ECH and ECCD can stabilize (increasing the period and amplitude) the sawteeth when the deposition is near the region of the $q=1$ surface. ${ }^{19,20}$ Experiments on both TCV and ASDEX-upgrade ${ }^{21}$ have shown that the maximum in the sawtooth period occurs when the ECH deposition $\left(\rho_{\text {dep }}\right)$ is outside the sawtooth inversion radius $\left(\rho_{\text {ST-IR }}\right)$, this location is referred to as $\rho_{\text {ST-max }} \cdot{ }^{22}$ This effect has been predicted by the PRETOR-ST transport code, ${ }^{23}$ which includes a sawtooth period model that triggers a sawtooth crash when the magnetic shear at $q=1$ reaches a critical value, depending on local plasma parameters. ${ }^{24}$ The sawteeth have also been shown to be further stabilized (respectively destabilized) when the ECH is replaced with co-ECCD (respectively counter-ECCD) on $\rho_{\text {ST-max }}$. Since the sawtooth period decreases linearly with the negative current driven on $\rho_{\text {ST-max }}$ (Refs. 19, 20, 22) counter-ECCD on $\rho_{\text {ST-max }}$ offers the potential to destabilize the sawteeth and to avoid the onset of the NTM instability.

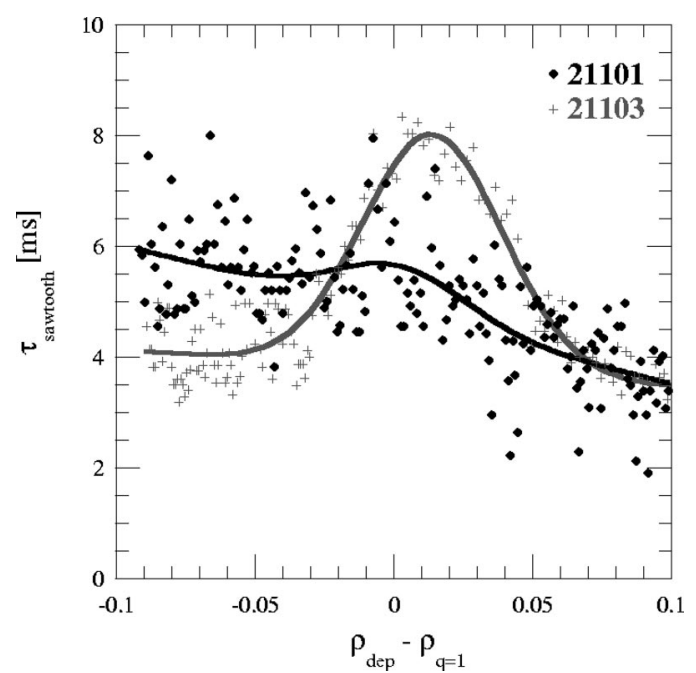

FIG. 3. The effect of the ECH deposition location relative to the $q=1$ surface on the sawtooth period. Pulse \#21103 has 1.35 MW swept through the $q=1$ region with the sawtooth period peaking outside the $q=1$ surface. Pulse \#21101 is identical to pulse \#21103 except for an additional 0.45 MW deposited inside the $q=1$ surface (Ref. 25).

Experiments on TCV have demonstrated that the sawtooth period can be reduced with ECH deposition slightly inside the $q=1$ surface $\left(\rho_{q=1}\right)$. Using $1.35 \mathrm{MW} \mathrm{X} 2$ power and sweeping the beams across the $q=1$ region, the sawtooth period $\left(\tau_{S T}\right)$ reaches a maximum $\left(\tau_{\mathrm{ST}} \sim 8 \mathrm{~ms}\right.$ vs $\tau_{\mathrm{ST}-\text { ohmic }} \sim 2.4 \mathrm{~ms}$ ) when $\rho_{\text {dep }}>\rho_{q=1}$, see Fig. 3 (pulse \#21103). The same sweep with an additional 0.45 MW of ECH applied just inside the $q=1$ surface $\left(\rho_{\text {dep }}-\rho_{q=1}\right.$ $\approx-0.22$ ) showed a reduction of the peak sawtooth period from $8 \mathrm{~ms}$ to $5.5 \mathrm{~ms}$ when $\rho_{\text {dep }}=\rho_{\text {ST-max }}$, as shown in Fig. 3 (pulse \#21101). The additional power deposited inside $\rho_{q=1}$ prevents the stabilization of the sawteeth when the swept beams are at $\rho_{\text {ST-max }}$. This demonstrates that a small amount of very localized ECH power can significantly reduce the sawtooth period. ${ }^{25}$ When the swept beams are deposited inside $\rho_{q=1}$, the additional $0.45 \mathrm{MW}$ increases the sawtooth period, as the latter is proportional to the power deposited inside $q=1$ in this case.

PRETOR-ST had successfully modeled the above results and was then applied in a predictive mode to determine the effect of sweeping one beam through the cross section of the plasma while maintaining three beams on $\rho_{\text {ST-max }}$. The simulation predicted that the sawtooth period would exhibit a minimum when the deposition of the swept beam was just inside the $q=1$ surface, and a maximum just outside. ${ }^{25}$ The variation in the sawtooth period during the experimental sweep is compared to the PRETOR-ST prediction in Fig. $4 .{ }^{22}$ The general dependence of the sawtooth period as a function of the distance from the $q=1$ surface is similar in the experiment and the model although the distance of the maximum and minimum from the $q=1$ surface is slightly overestimated by the model. This is attributed to a narrower ECH deposition profile as well as to a small co-ECCD injection angle of the fixed beams in the experiment, which tends to move both $\rho_{\text {ST-max }}$ and $\rho_{\text {ST-min }}$ toward the $q=1$ surface and increase the sawtooth period. ${ }^{25}$ According to simulations the 


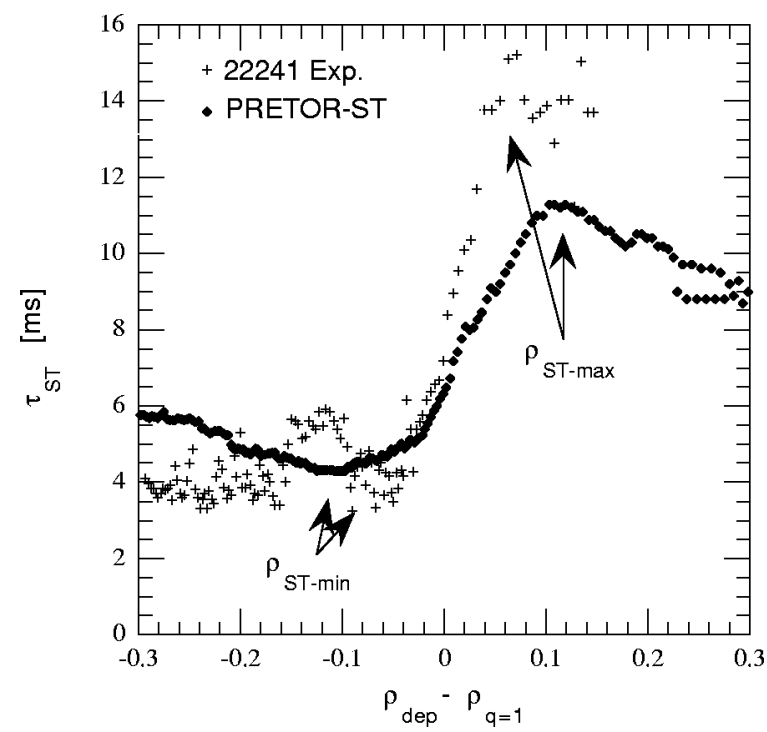

FIG. 4. Comparison of the sawtooth period from the PRETOR-ST theoretical prediction and experiment due to a single swept beam $(0.45 \mathrm{MW})$ across the $q=1$ region with $1.35 \mathrm{MW}$ (respectively $0.9 \mathrm{MW}$ ) deposited on $\rho_{\mathrm{ST}-\max }$ for the theoretical prediction (respectively experiment) (Ref. 22).

most efficient method for destabilizing (respectively stabilizing) sawteeth is with co-ECCD inside (respectively outside) the $q=1$ surface. ${ }^{25}$ The decrease in the sawtooth period from $\sim 7.5 \mathrm{~ms}$ (1.35 MW on $\rho_{\text {ST-max }}$ ) to $4 \mathrm{~ms}$ (near Ohmic levels) when the ECH deposition is at $\rho_{\mathrm{ST} \text {-min }}$ demonstrates the capability of ECH to destabilize the sawtooth instability, which offers the possibility of avoiding sawtooth triggered NTMs by keeping the sawtooth related seed islands below the critical size.

\section{ELECTRON ITB FORMATION IN STEADY STATE REGIME}

Previous experiments on TCV have achieved fully sustained noninductive discharges by replacing the inductively driven current with co-ECCD, ${ }^{7,8}$ The co-ECCD deposition is distributed across the discharge to obtain a stable driven current profile. These fully sustained discharges have been extended to advanced tokamak regimes; specifically the generation of reversed central shear and an electron internal transport barrier (eITB) in conjunction with a large bootstrap current fraction (up to $80 \%$ of the total current) in steady state with no inductively driven current. ${ }^{26,27}$ The co-ECCD deposition is moved off-axis with the intention of creating a hollow current profile. However, owing to the transport of energetic electrons, the resulting ECCD current profile is calculated to be centrally peaked or flat. ${ }^{26-30}$ The broader current profile nevertheless improves the central confinement, causing an increase in the electron temperature and pressure gradients and thus, in turn, increasing the bootstrap current, which reaches $\sim 30 \%$ of the total plasma current. The broad ECCD profile and the large off-axis bootstrap current form a hollow current profile. Once this hollow current profile is established, an additional 0.45 MW ECH power is deposited centrally resulting in a rapid increase in the central temperature $\left(T_{e 0}\right)$ and also in the electron energy confinement time
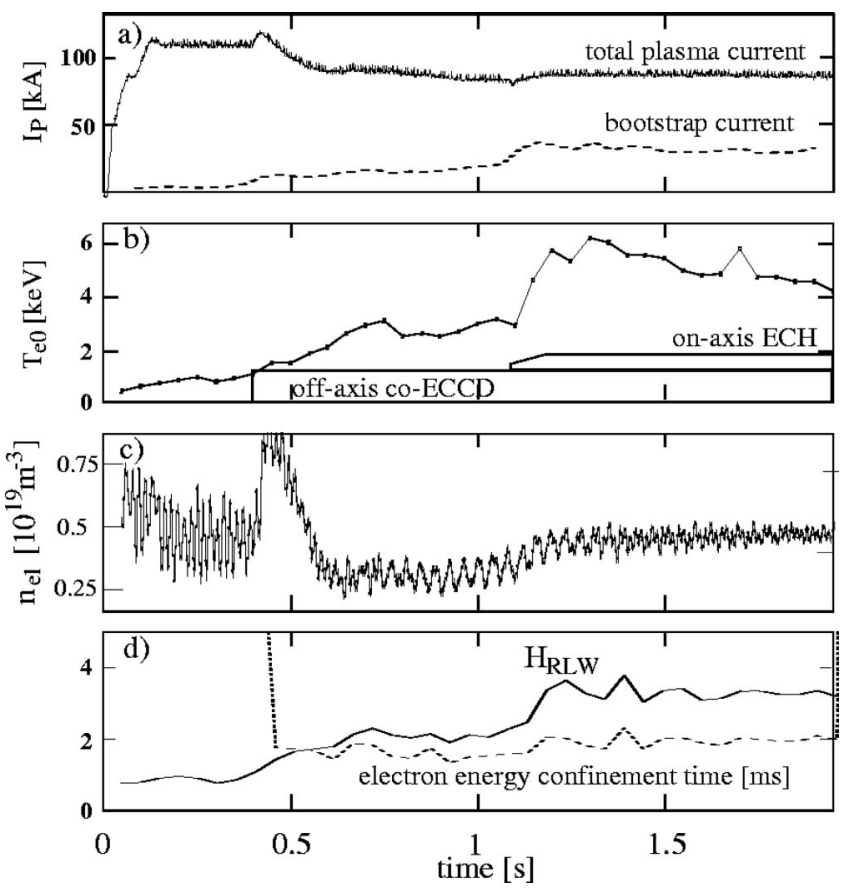

FIG. 5. (a) The plasma current is sustained by two off axis co-ECCD beams and a large bootstrap current; at $1.1 \mathrm{~s}$ central heating is added resulting in a fast rise in (b) the central temperature, (c) line averaged density, and (d) the confinement enhancement factor.

$\left(\tau_{E e}\right)$ despite the power increase (see Fig. 5). This is in contrast to L-mode scaling laws, which show a decrease in confinement with additional heating. Similar results have been observed in centrally heated eITB's on JT-60U. ${ }^{31}$ The rapid increase in the central electron temperature, on the time scale of $\tau_{E e}$, suggests that the conditions for the eITB are already established before the addition of the central heating. In these low density discharges with high ECH injected power, the electron temperature can be significantly higher than the ion temperatures $\left(T_{e} \sim 25 T_{i}\right)$. The value of $\tau_{E e}$ is evaluated with respect to the Rebut-Lallia-Watkins scaling ${ }^{32}$ ( $H_{\mathrm{RLW}}$ $\left.=\tau_{E e} / \tau_{\mathrm{RLW}}\right)$, as this scaling has been shown to model the TCV ECH heated L-mode ${ }^{33}$ well and it gives $H_{R L W}=1$ in Ohmic conditions. $H_{\text {RLW' }}$ 's of $\sim 3.5$ have been achieved in steady state scenarios lasting up to $1000 \tau_{E e}$ or 10 current redistribution time scales $\left(\tau_{\mathrm{CRT}}\right)$ on TCV $\left(\tau_{\mathrm{CRT}}\right.$ is measured as the $e$-fold time for the plasma internal inductance to stabilize during the transition from inductively driven to fully ECCD sustained current and is of the order of $\sim 175 \mathrm{~ms}$ ).

These centrally heated eITB's have high central pressure which further steepens the pressure gradient off-axis, increasing the bootstrap current and deepening the hollow current profile, as shown in Fig. 6. The plasma current density profile is calculated by adding the ECCD current profile (as calculated by the CQL3D quasilinear Fokker-Planck code ${ }^{34}$ ) to the bootstrap current profile (calculated from the Thomson scattering measurement of the pressure profile ${ }^{35}$ ). A fixed boundary equilibrium code then uses this current profile and the measured pressure profile as a source term to calculate the $q$ profile and yields a reversed shear as shown in Fig. 6 . Thus, the enhanced confinement can be attributed to reversed central shear with the global shear reversal factor given as 


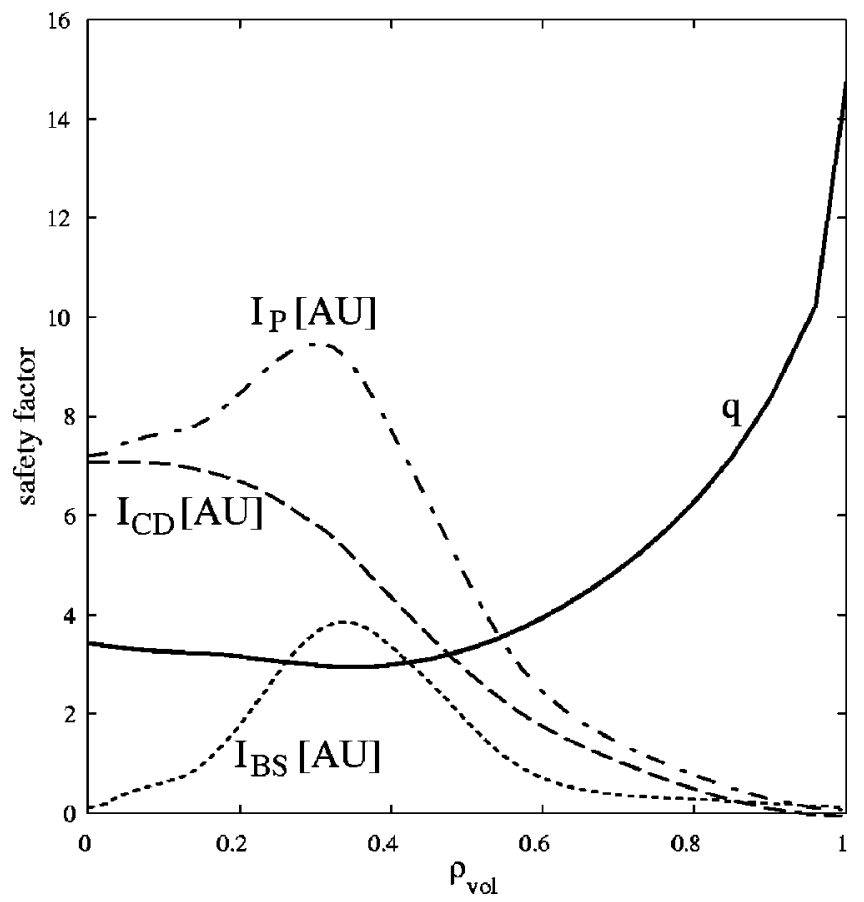

FIG. 6. The sum of the off-axis driven current and a large bootstrap current results in a calculated hollow current density profile and a reversed shear $q$ profile. The discharge was maintained with $0.9 \mathrm{MW}$ of co-ECCD off axis and $0.45 \mathrm{MW}$ of counter-ECCD on axis.

$q_{0} / q_{\text {min }} \approx 3.9 / 3.2$. Note that the eITB is generated and maintained under steady-state plasma conditions, in particular as there is no inductive Ohmic current.

The creation of the eITB is dependent upon the deposition location of the off-axis co-ECCD. To illustrate this, a scan of the radial deposition location of the off-axis coECCD $\left(\rho_{\text {co-dep }}\right)$ was performed on a pulse-to-pulse basis, with central ECH added for each pulse in the second half of the discharge. Significant improvement in confinement is achieved in the second half of the discharge only when $\rho_{\text {co-dep }}$ exceeds 0.3, as shown in Fig. 7. The $q$ profiles of the

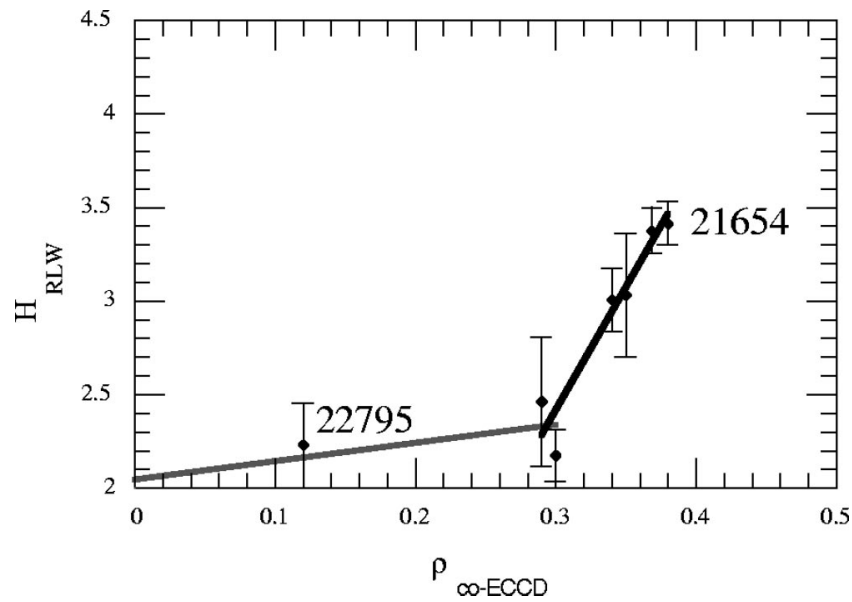

FIG. 7. Dependence of the confinement enhancement factor on the radial position of the off-axis co-ECCD deposition location. Significant improvement in confinement is observed when the off-axis co-ECCD is outside $\rho$ $=0.3$.
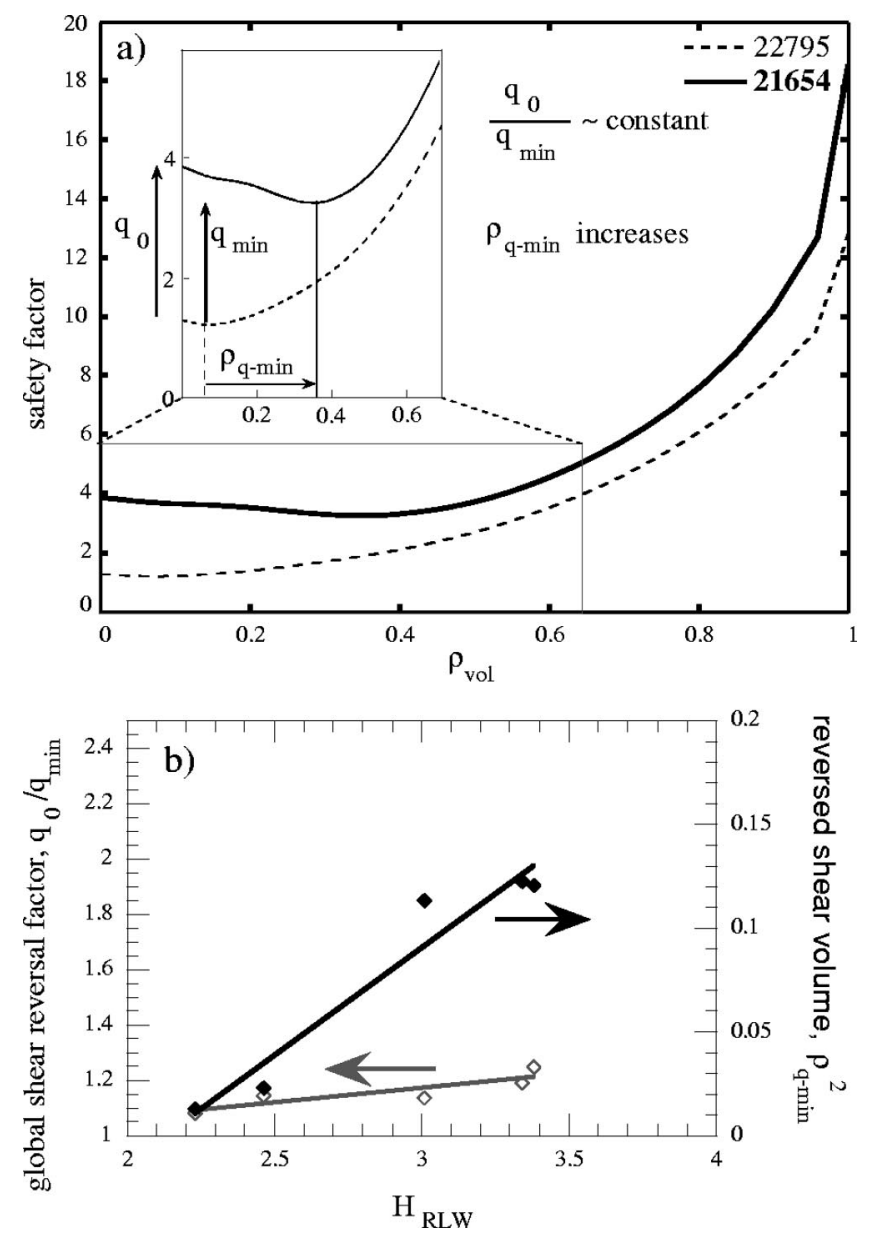

FIG. 8. (a) Safety factor profiles for off-axis co-ECCD deposition near the center (\#22795) and far from the center (\#21654). The change in the deposition location increases the volume enclosed within the reversed shear region $\left(\rho_{q \text {-min }}^{2}\right)$ while maintaining a nearly constant global shear reversal factor $\left(q_{0} / q_{\mathrm{min}}\right)$. The improved confinement is attributed to the increase of the reversed shear volume as shown in (b).

two extrema of the scan are shown in Fig. 8(a); the improved confinement is associated with an enlargement of the volume enclosed in the reversed shear region which is proportional to $\rho_{q \text {-min }}^{2}$ (where $\rho_{q \text {-min }}$ is the radial location of the minimum in $q$ ), see Fig. 8(b). Note that the global shear reversal factor remains relatively small $\left(q_{0} / q_{\min }<1.2\right)$.

Replacing the central heating with counter (respectively co) ECCD increases (respectively decreases) the confinement enhancement, as shown in Fig. 9. The improved confinement, $H_{\text {RLW }} \approx 4.5$ [or $H_{\text {ITER-98L }}$ (Ref. 36$) \approx 1.6$ ], is associated with an increase in the global shear reversal factor and the reversed shear volume as shown in Fig. 10. Further increasing the counter current on axis creates strongly peaked profiles $\left(H_{\mathrm{RLW}}>5\right)$ resulting in MHD modes and/or plasma disruption. The onset of the MHD modes can be avoided reliably by reducing the level of counter-ECCD on axis to just below the MHD threshold.

Since $\rho_{\text {co-dep }}$ and the amount of ECCD on-axis affect $q_{0} / q_{\min }$ and $\rho_{q \text {-min }}^{2}$ differently [see Figs. $8(\mathrm{~b})$ and $10(\mathrm{~b})$ ], it should be possible to control either the global shear reversal factor or the volume independently. The database of all 


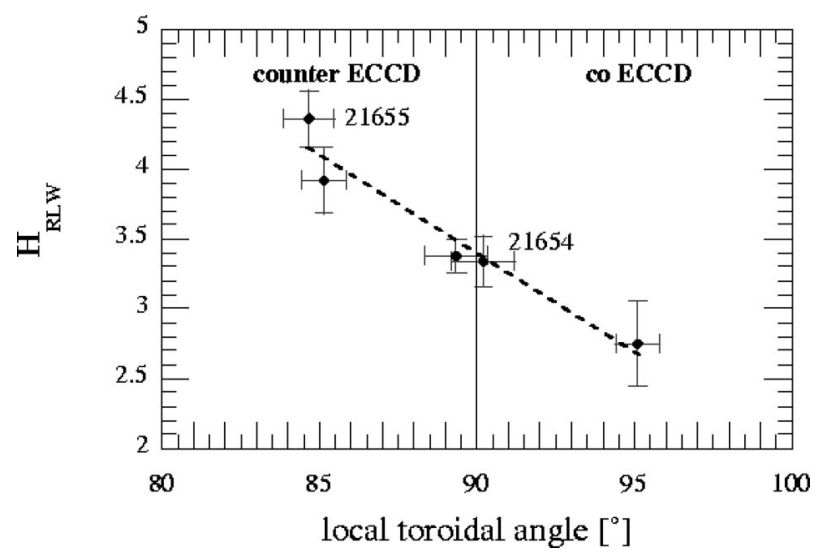

FIG. 9. The confinement enhancement factor, $H_{\mathrm{RLW}}$, increases linearly with the local toroidal angle (angle between ECH beam and the magnetic field line at the resonant surface) of the centrally deposited $0.45 \mathrm{MW}$ beam in the second phase of the discharge.

eITB's created and maintained in stable scenarios with $\rho_{q \text {-min }}$ ranging from 0.1 to 0.4 and $q_{0} / q_{\min }$ values from 1.1 to 3.6 reveals a linear dependence of the improved confinement, $H_{\mathrm{RLW}}$, on a figure of merit defined as the product of the
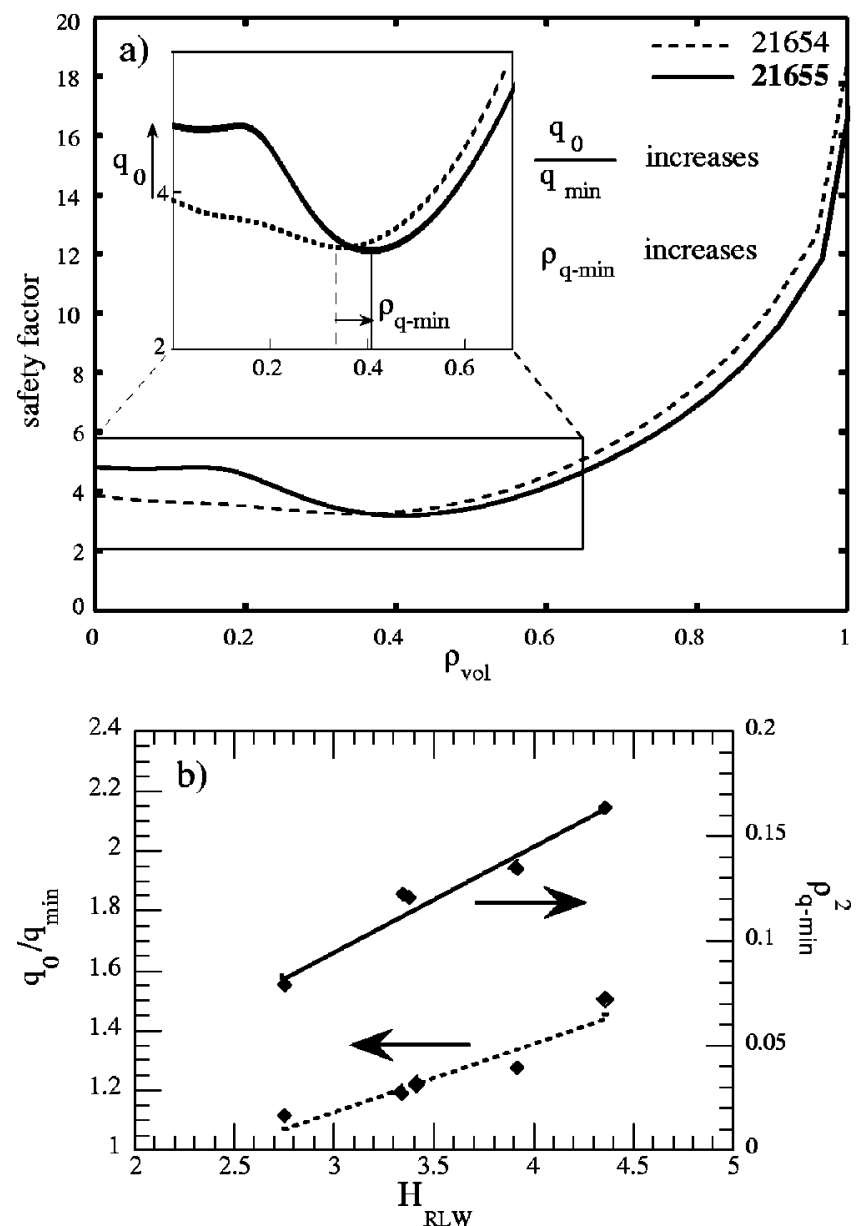

FIG. 10. (a) Safety factor profiles for discharges with on-axis counterECCD (\#21655) and ECH (\#21654), respectively. Both the volume enclosed within the reversed shear region $\left(\rho_{q \text {-min }}^{2}\right)$ and the global shear reversal factor $\left(q_{0} / q_{\mathrm{min}}\right)$ increase with the injection of counter-ECCD. The improved confinement is associated with an increase of both $\rho_{q-\min }^{2}$ and $q_{0} / q_{\min }$ as shown in (b).

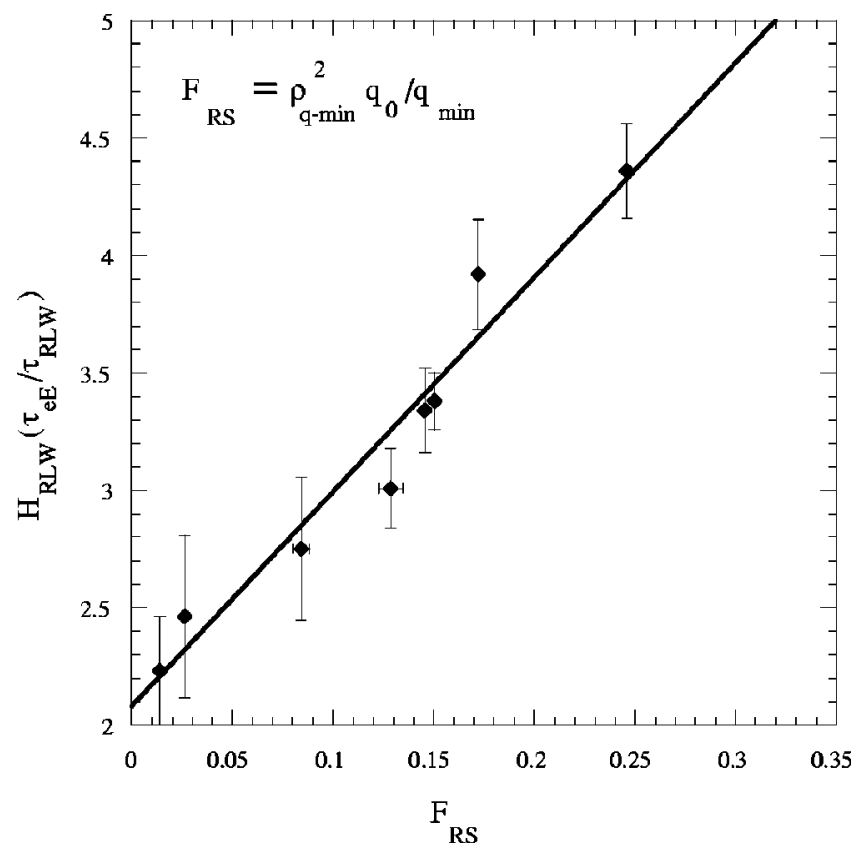

FIG. 11. A figure of merit of the reversed shear discharges is given as the product of the global shear reversal factor and the reverse shear volume, $F_{\mathrm{RS}}=\rho_{q-\min }^{2} \cdot q_{0} / q_{\min }$. The confinement enhancement factor, $H_{\mathrm{RLW}}$, scales linearly with $F_{\mathrm{RS}}$.

global shear reversal factor and the reversed shear volume, $F_{\mathrm{RS}}=\rho_{q-\min }^{2}\left(q_{0} / q_{\text {min }}\right)$, as shown in Fig. 11 . The linear dependence of $H_{\mathrm{RLW}}$ on $F_{\mathrm{RS}}$ demonstrates the gradual improvement of confinement using the current tailoring capabilities of ECCD.

A maximum bootstrap current fraction of $\sim 80 \%$ has been achieved in these sustained eITB discharges by adding additional ECH power both on-axis (0.45 MW) and off-axis $(0.45 \mathrm{MW})$ and increasing the plasma density. ${ }^{26,27,30}$ The added power increases the pressure gradient leading to a larger bootstrap current while the increased density decreases the current drive efficiency and thus increases the bootstrap current fraction. The $80 \%$ bootstrap current fraction discharges have been sustained for $\sim 5 \tau_{\mathrm{CRT}}$ with an average $H_{\mathrm{RLW}}$ of 3.7. The eITB position is observed to remain constant.

\section{CONCLUSION}

The X3 system is now complete and has demonstrated heating of high-density plasmas not previously possible on $\mathrm{TCV}$, opening the way for future studies of reactor-relevant high-beta regimes. Single pass absorption of up to $100 \%$ has been achieved with top launch X3. The benefit of the specific launcher geometry chosen in TCV, allowing an increase interaction of the beam with the EC resonance, has been demonstrated and corresponds to the prediction.

In a different study, a small amount of ECH power deposited just inside (respectively outside) the $q=1$ surface has been shown to significantly destabilize (respectively stabilize) the sawtooth period. Sawteeth extended to a $\sim 15 \mathrm{~ms}$ period by $0.9 \mathrm{MW}$ co-ECCD deposited outside the $q=1$ surface have been destabilized by the added power to $\sim 4 \mathrm{~ms}$ 
close to Ohmic values. This sawtooth destabilization tool may be used to prevent long sawtooth periods, which have been shown to trigger the onset of NTMs in low beta discharges on JET, similar to the operating regimes planned for ITER.

Electron ITB's have been created in stable plasma conditions lasting for up to 10 current redistribution times and with a confinement enhancement of up to $H_{\mathrm{RLW}} \sim 4.5$ or $H_{\text {ITER98-L }} \sim 1.6$. The plasma current was driven fully noninductively with a high bootstrap current fraction approaching $\sim 80 \%$ in some cases; the duration of the eITB was limited only by the gyrotron pulse length. The eITB position is in steady-state as well and therefore well-aligned with the resulting $q$ profile, which in turn determines the improved confinement region. The confinement improvement scales linearly with a global reversed shear figure of merit, $F_{\mathrm{RS}}$, equal to the product of the global shear reversal factor $\left(q_{0} / q_{\text {min }}\right)$ and the volume enclosed in the reversed shear region $\left(\rho_{q-\min }^{2}\right)$. This remarkably steady eITB position shows that the coupled system of driven and bootstrap currents along with the heat and particle flux transport can be maintained in steady-state in a regime of enhanced performance.

\section{ACKNOWLEDGMENT}

This work was supported in part by the Swiss National Science Foundation.

${ }^{1}$ T. P. Goodman, S. Alberti, M. A. Henderson, A. Pochelon, and M. Q. Tran, in Proceedings of the 19th Symposium on Fusion Technology, Lisbon, 1996 (Elsevier, Amsterdam, 1997), p. 565.

${ }^{2}$ J.-P. Hogge, S. Alberti, L. Porte, and G. Arnoux, in Proceedings of the 12th Joint Workshop on ECE and ECRH, 12-15 May 2002 Aix-enProvence (World Scientific, Singapore, 2003), p. 371.

${ }^{3}$ F. Hofmann, J. B. Lister, M. Anton et al., Plasma Phys. Controlled Fusion 36, B277 (1994).

${ }^{4}$ R. Aymar, Plasma Phys. Controlled Fusion 42, B385 (2000).

${ }^{5}$ O. Sauter, E. Westerhof, M. L. Mayoral et al., Phys. Rev. Lett. 88, 105001 (2002).

${ }^{6}$ J. Pamela, S. Alberti, S. Allfrey et al., 18th IAEA-FEC (IAEA, Vienna, 2001), PD1.

${ }^{7}$ O. Sauter, M. A. Henderson, F. Hofmann et al., Phys. Rev. Lett. 84, 3322 (2000).

${ }^{8}$ S. Coda, T. P. Goodman, M. A. Henderson, F. Hofmann, Z. A. Pietrzyk, O. Suater et al., Plasma Phys. Controlled Fusion 42, B311 (2000).

${ }^{9}$ G. Arnoux, A. Manini, J.-M. Moret, and S. Alberti, in Proceedings of the 29th EPS Conference on Plasma Physics and Controlled Fusion, 17-21 June 2002, Montreux, Vol. 26B, p. 2.076.

${ }^{10}$ K. Matsuda, IEEE Trans. Plasma Sci. PS-17, 6 (1989).

${ }^{11}$ R. H. Cohen, Phys. Fluids 30, 2442 (1987).

${ }^{12}$ A. Manini, J.-M. Moret, S. Alberti, T. P. Goodman, and M. A. Henderson, Plasma Phys. Controlled Fusion 44, 139 (2002).

${ }^{13}$ S. Alberti, L. Porte, G. Arnoux, T. P. Goodman, M. A. Henderson, J.-P. Hogge, and E. Nelson-Melby, in Proceedings of the 29th EPS Conference on Plasma Physics and Controlled Fusion, 17-21 June 2002, Montreux, Europhysics Conference Abstracts Vol. 26B, p. 2-073.
${ }^{14}$ L. Porte, S. Alberti, G. Arnoux, Y. Martin, J.-P. Hogge, T. P. Goodman, M. A. Henderson, E. Nelson-Melby, A. Pochelon, and M. Q. Tran, 19th IAEAFEC (IAEA, Vienna, 2002), EXP5/15.

${ }^{15}$ Y. Camenen, A. Pochelon, F. Hofmann, C. Angioni, T. P. Goodman, M. A. Henderson, P. Nikkola, L. Porte, and O. Sauter, in Proceedings of the 12th Joint Workshop on ECE and ECRH, 12-15 May 2002, Aix-en-Provence (World Scientific, Singapore, 2003), p. 407.

${ }^{16}$ A. Pochelon, G. Arnoux, Y. Camenen, A. Scarabosio et al., 19th IAEAFEC (IAEA, Vienna, 2002), EXP5/14.

${ }^{17}$ F. Hofmann, R. Behn, S. Coda et al., Plasma Phys. Controlled Fusion 43, A161 (2001)

${ }^{18}$ S. Alberti, T. P. Goodman, M. A. Henderson, A. Manini, J.-M. Moret, P. Gomez, P. Blanchard, S. Coda, O. Sauter, Y. Peysson, and TCV Team, Nucl. Fusion 42, 42 (2002).

${ }^{19}$ T. P. Goodman, 18th IAEA-FEC (IAEA, Vienna, 2001), EXP4/09.

${ }^{20}$ M. A. Henderson, T. P. Goodman, J.-P. Hogge, Z. A. Pietrzyk, A. Pochelon, and O. Sauter, Fusion Eng. Des. 53, 241 (2001).

${ }^{21}$ A. C. C. Sips, R. Arslanbekov, C. Atanasiu et al., Plasma Phys. Controlled Fusion 44, B69 (2002).

${ }^{22}$ T. P. Goodman, A. Mück, C. Angioni, M. A. Henderson, O. Sauter, F. Ryter, E. Westerhof, H. Zohm, and ASDEX-upgrade Team, 19th IAEAFEC (IAEA, Vienna, 2002), EXP5/11.

${ }^{23}$ C. Angioni, T. P. Goodman, Z. A. Pietrzyk, and O. Sauter, Theory of Fusion Plasmas (Editrice Compositori, Bologna, 2002), p. 73.

${ }^{24}$ F. Porcelli, D. Boucher, and M. N. Rosenbluth, Plasma Phys. Controlled Fusion 38, 2163 (1996)

${ }^{25}$ C. Angioni, T. P. Goodman, M. A. Henderson, and O. Sauter, "Effects of localized electron heating and current drive on the sawtooth period," Nucl. Fusion (submitted).

${ }^{26}$ O. Sauter, R. Behn, S. Coda, I. Condrea, T. P. Goodman, M. A. Henderson, and P. Nikkola, in Proceedings of the 29th EPS Conference on Plasma Physics and Controlled Fusion, 17-21 June 2002, Montreux, Europhysics Conference Abstracts Vol. 26B, p. 2-087.

${ }^{27}$ T. P. Goodman, R. Behn, S. Coda, I. Condrea, M. A. Henderson, P. Nikkola, and O. Sauter, in Proceedings of the 29th EPS Conference on Plasma Physics and Controlled Fusion, 17-21 June 2002, Montreux, Europhysics Conference Abstracts Vol. 26B, p. 2-081.

${ }^{28}$ P. Nikkola, O. Sauter, R. Behn, S. Coda, I. Condrea, T. P. Goodman, M. A. Henderson, R. W. Harvey, Y. Peysson, and TCV Team, in Proceedings of the 12th Joint Workshop on ECE and ECRH, 12-15 May 2002, Aix-enProvence (World Scientific, Singapore, 2003), p. 257.

${ }^{29}$ P. Nikkola, O. Sauter, R. Behn, S. Coda, I. Condrea, T. P. Goodman, M. A. Henderson, R. W. Harvey, and TCV Team, "Modeling of the electron cyclotron current drive experiments in the TCV tokamak," Nucl. Fusion (submitted).

${ }^{30}$ O. Sauter, C. Angioni, R. Behn et al., 19th IAEA-FEC (IAEA, Vienna, 2002), EXP5/06.

${ }^{31}$ Y. Ikeda, T. Suzuki, A. Isayama et al., in Proceedings of the 12th Joint Workshop on ECE and ECRH, 12-15 May 2002, Aix-en-Provence (World Scientific, Singapore, 2003), p. 247.

${ }^{32}$ P. H. Rebut, P. P. Lallia, and M. L. Watkins, in Proceedings of the 12 th International Conference of Plasma Physics and Controlled Fusion Research, Nice, 1988 (IAEA, Vienna, 1989), Vol. 2, p. 191.

${ }^{33}$ A. Pochelon, T. P. Goodman, M. A. Henderson et al., Nucl. Fusion 39, 1807 (1999).

${ }^{34}$ R. W. Harvey and M. G. McCoy, in Proceedings of the IAEA Technical Committee Meeting on Numerical Modeling of Plasmas, Montreal, 1992 (IAEA, Vienna, 1993).

${ }^{35}$ O. Sauter, C. Angioni, and Y. R. Lin-Liu, Phys. Plasmas 6, 2834 (1999); 9 5140(E) (2002).

${ }^{36}$ ITER Global Data Base Working Group, 17th IAEA-FEC (IAEA, Vienna, 2001), ITERP1/7. 